\title{
Effect of Nanopowder Concentration on Material Wear Resistance
}

\author{
Nadezhda S. KHITERHEEVA ${ }^{1,2^{*}}$, Sofya A. PETROVA ${ }^{1,3}$, Varvara P. DRUZHNOVA ${ }^{1,3}$, \\ Petr A. BOLOEV ${ }^{2}$, Nikolay I. MOSHKIN ${ }^{2}$. Marfa K. OKHLOPKOVA ${ }^{1,3}$, \\ and Zhargal N. BOTOEV ${ }^{4}$ \\ ${ }^{1}$ Oktemsky Branch Yakutsk State Agricultural Academy, Oktemtsy, \\ Republic of Sakha (Yakutia), Russian Federation \\ ${ }^{2}$ Buryat State University, Ulan-Ude, Republic of Buryatia, Russian Federation \\ ${ }^{3}$ North-Eastern Federal University named after M.K. Ammosov, Yakutsk, \\ Republic of Sakha (Yakutia), Russian Federation \\ ${ }^{4}$ Institute of Physical Material Science of the Siberian Branch of the Russian Academy of Sciences, \\ Ulan-Ude, Republic of Buryatia, Russian Federation \\ *Correspondence: kite69@yandex.ru
}

\begin{abstract}
The article presents the materials of experiments to improve the friction characteristics to reduce the wear of the piston material of the 3S-FE internal combustion engine. Changing the friction characteristics was carried out using additives in engine oil, prepared on the basis of nanosized powder of silicon dioxide. The experiments were carried out at different concentrations of nanopowder in oil $(0.9 \% ; 1.7 \% ; 2.5 \% ; 3.4 \%)$. To develop additives of different compositions, the method of ultrasonic dispersion in the regime of acoustic cavitation on the IL 100/6 installation was used. In order to conduct experiments to determine the wear of a material, an experimental setup called "friction machine" was developed. The studied samples of the material that come into contact with a rotating disc are fixed in a special lever groove. An additional effect on the contact zone was regulated with the help of weights placed at the end of the lever handle. The mass of the cargo was $9 \mathrm{~kg}$ under the conditions of the experiment. To use the lubrication of the contact zone, a bath is provided in which the tested samples of modified engine oil are poured. The rotating disk was partially immersed in oil, providing conditions for self-lubrication. The experiments showed the economic feasibility of using nanosized powder of silicon dioxide as a friction modifier. The optimal nanopowder concentrations were revealed at which the wear is minimal. The possibility of increasing the life of an internal combustion engine between repairs by 2-3 times is shown.
\end{abstract}

Keywords: friction, wear resistance, engine oil, additive, nanopowder.

\section{Introduction}

In recent years the quality of lubricants which include motor oils has improved significantly due to a whole package of complex and perfect additives (antifriction, antioxidant, viscous, detergents, etc.), which significantly reduce the wear rate, protect against deposits and corrosion, create normal working conditions in extreme conditions. 
At present synthetic motor oils are widely used. They have a low pour point, high thermal stability and pumpability, good lubricating and viscosity-temperature properties, which provide easy starting of a cold engine and are resistant to oxidation. The use of such oils significantly reduces the wear rate of structural elements of the engine and increases its resource $[1$, p. 251].

The degree of protection of engine parts of agricultural machines from wear increases with the growth of the operational properties of oil. The life of the engine is increased according to the theory of reliability. The period of planned wear and the time between repairs are extended. Thus, it becomes economically viable to use engine oils with improved performance properties.

One way to improve the properties of motor oil is to use additives. Additives can change various properties of motor oil (viscous, detergent, antifreeze, etc.). Our study was aimed at the getting an additive in motor oil, the main task of which is to improve the friction characteristics in the contact zone of materials where maximum wear occurs.

\section{Materials and Methods}

A patented additive in motor oil made at the Small Innovative Enterprise LLC "NANOCHIT" at the Buryat State University was used for the experiments [2]. A patented method of getting an additive in engine oil is based on the use of nanosized powder of silicon dioxide.

The method for producing the additive is based on the method of ultrasonic dispersion and deagglomeration of nanosized powders [3, 4]. We improved this method. The ultrasound is used in acoustic cavitation mode, so there is a significant intensification of the process. Processing time is reduced by an order of magnitude, which leads to significant savings in energy consumption. The dispersion installation contains: an ultrasonic frequency generator IL 100/6 (manufactured in the Russian Federation, St. Petersburg); magnetostrictive converter, a waveguide (concentrator) of acoustic energy, a capacity for dispersing, hoses for supplying coolant to the cooling jacket of the magnetostrictive converter. The generator with the converter is connected by a flexible protected wire. For the convenience of conducting experiments, the converter with the waveguide is mounted in a special tripod with the possibility of vertical movement.

Four compositions were prepared at the installation. The nanopowder content of compositions was the following: $0.9 \% ; 1.7 \% ; 2.5 \% ; 3.4 \%$. Nano- and micro-sized powders have recently been used to improve the friction characteristics and increase the wear resistance of materials $[5,6]$. Nanopowders were dispersed in base engine oil compatible with all types of engine oils.

To prepare the additive, we used silicon dioxide nanopowder produced by LLC "Bardakhanov" under the trade name "Tarkosil" by the method of gas-phase evaporation [7]. The dimension of the powder is $50 \mathrm{~nm}$. The process is based on the evaporation of the starting material under the influence of an electron beam created by an electron accelerator. It is noteworthy that the production of Tarkosil goes without a special atmosphere in the open air. After evaporation the atoms of the substance are captured by a stream of cold air, cooled and coagulated (they form agglomerates). The powder is unloaded (from cyclones and from the filter) in various elements of the installation. After filtering the air goes through the pipe into the street. The formation of hazardous 
radioactive isotopes is impossible due to the not too high beam energy (1.4 MeV). So the resulting powder is absolutely harmless.

The material of the piston of the internal combustion engine 3S-FE was used as samples for wear tests. Samples were cut on the machine in the form of a parallelepiped (cubes) of the same size. One surface of the "cube" that interacted with another part, forming a pair of friction, was carefully processed (grinded, degreased). And also it was photographed on a microscope. Under the conditions of severe friction a "contact spot" will be formed on this surface during this experiment. Before the experiment each "cube" was weighed on the electronic scales accurate to 4 decimal places.

The experiments to determine the wear resistance of the surface at different concentrations of nanosized particles were carried out on a designed experimental setup with the code name "friction machine". A friction machine is a device that is designed to study the tribological process under controlled conditions, the contact interaction of rubbing surfaces during their relative movement [8]. A photograph of the installation is shown in Figure 1.

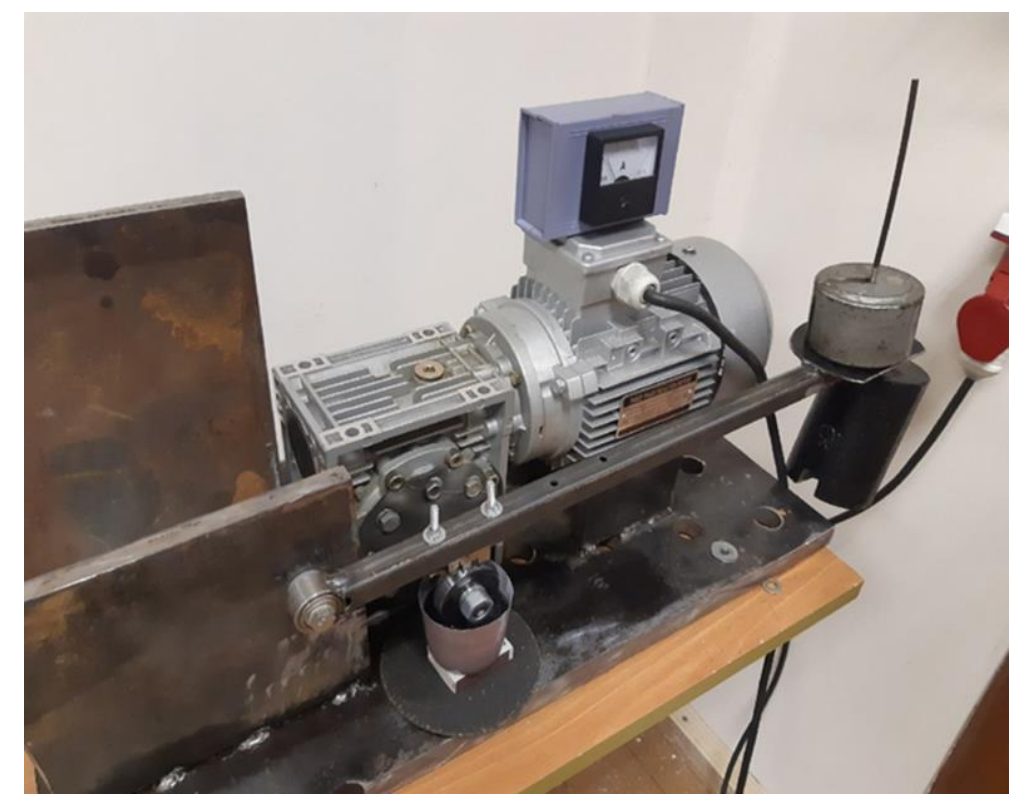

Figure 1. General view of the "friction machine"

The installation consists of a worm gear driven by a $1.5 \mathrm{~kW}$ induction motor. A highstrength steel wheel (disk) is installed on the output shaft of the gearbox, which can rotate with a frequency equal to the gearbox output shaft speed. Prototypes of material that come into contact with a rotating disk are fixed in a special groove of the lever. The lever simultaneously serves to clamp the sample of the test material to the disk. The additional effect on the contact zone (additional clamping force) can be adjusted using weights placed on the end of the lever handle. The mass of the cargo was $9 \mathrm{~kg}$ under the conditions of the experiment. A bath is provided for lubrication. Oil with a different concentration of nanopowder was poured in the bath. A self-lubrication system was provided at the experiment. The oil was captured by a rotating disk and fed into the friction zone. 
The sequence of the experiment:

1. Grinding the surface of the experimental sample after measuring hardness and photographing the surface of the sample with an electron microscope.

2. Measurement of the mass of samples on the electronic scales before starting the experiments.

3. Degreasing the sample, friction wheel and container.

4. Installing the sample in the mounting location.

5. Filling the tank with the investigated liquid. (the container was thoroughly washed at each change of liquid).

6. Turning on the installation. The duration of the experiment was 1 hour for each sample.

7. Removing the sample from the installation. Oil cleaning, tank flushing.

8. Photographing the surface with an electron microscope.

9. Measurement of the mass of the sample after the experiment.

10. Processing the obtained results.

The surface hardness of the sample was measured by the express method using a porTable NOVOTEST hardness tester, according to the Rockwell method [9].

An additional experiment was conducted with base oil without the presence of nanopowder ("zero" concentration, sample 2) in addition to the listed samples tested at different concentrations. Thus, it was a "control" sample. Number 1 was an experiment on a sample without lubrication (dry friction).

\section{Results}

According to the results obtained during the experiment, it follows that the surfaces of the samples differ in a comparative visual analysis (see Figure 2). The results obtained are summarized in Table 1.

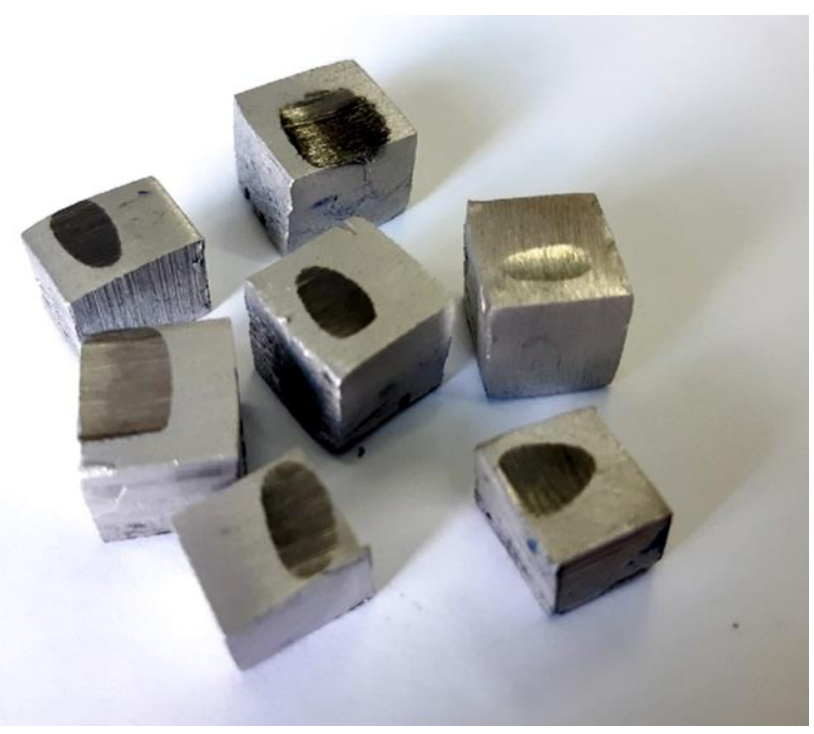

Figure 2. Metal samples after friction with contact spots 
Table 1. The weight of samples at different concentrations before and after the experiment

\begin{tabular}{|c|c|c|c|c|}
\hline № & Concentration, $\%$ & $\begin{array}{l}\text { Weight before } \\
\text { the experiment } \\
\text { kg } 10^{-3}\end{array}$ & $\begin{array}{l}\text { Weight after } \\
\text { the experiment } \\
\mathrm{kg} 10^{-3}\end{array}$ & $\begin{array}{c}\text { Absolute weight loss } \\
\Delta \mathrm{m}, \\
\mathbf{k g ~} 10^{-3}\end{array}$ \\
\hline 1 & dry & 2.7484 & 2.7363 & 0.0121 \\
\hline 2 & $0 \%$ & 2.5736 & 2.5669 & 0.0067 \\
\hline 3 & $0.9 \%$ & 2.3165 & 2.3134 & 0.0031 \\
\hline 4 & $1.7 \%$ & 2.6075 & 2.6030 & 0.0045 \\
\hline 5 & $2.5 \%$ & 2.5036 & 2.5011 & 0.0025 \\
\hline 6 & $3.4 \%$ & 2.9525 & 2.9442 & 0.0083 \\
\hline
\end{tabular}

Having learned the mass before and after friction, we conclude based on the results obtained that wear is reduced using additives. Studies have shown that metal wear differs from the control sample at different concentrations and under other identical conditions. The photograph (Figure 3) shows the samples with the smallest weight loss (least wear) at a concentration of $2.5 \%$ nanopowder in the base engine oil along with a control sample at a "zero" concentration.

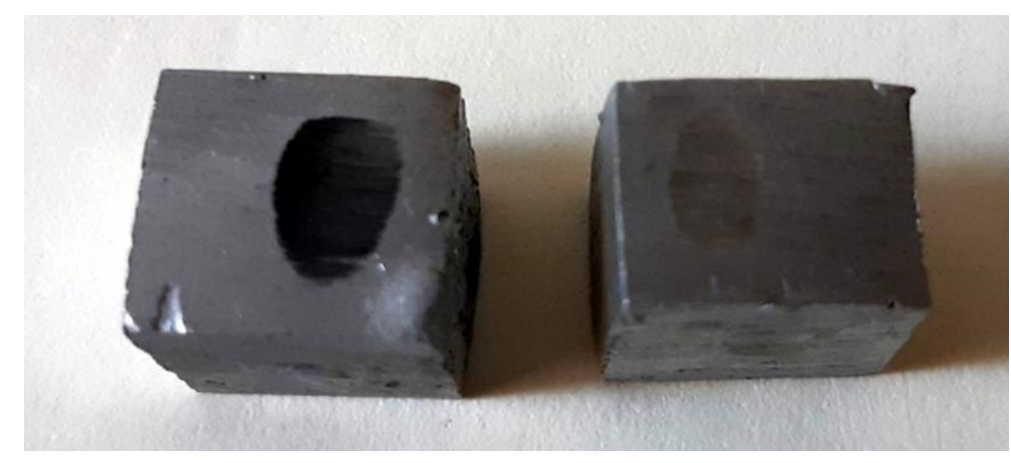

Figure 3. Photographs of samples after the experiment: a) control sample; b) a sample with minimal wear at a concentration of $2.5 \%$

According to the photograph, it is visually seen that the "contact spot" is smaller in size and depth (as evidenced by the mass measurement) with the addition of nanopowder, all other things being equal.

A columnar histogram was built (Figure 4) to see clearly the results of the experiments (Table 1).

It can be seen from it that the smallest weight loss has the sample No. 5 as a result of the experiments on the "friction machine". The concentration of nanopowder in motor oil was $2.5 \%$. 


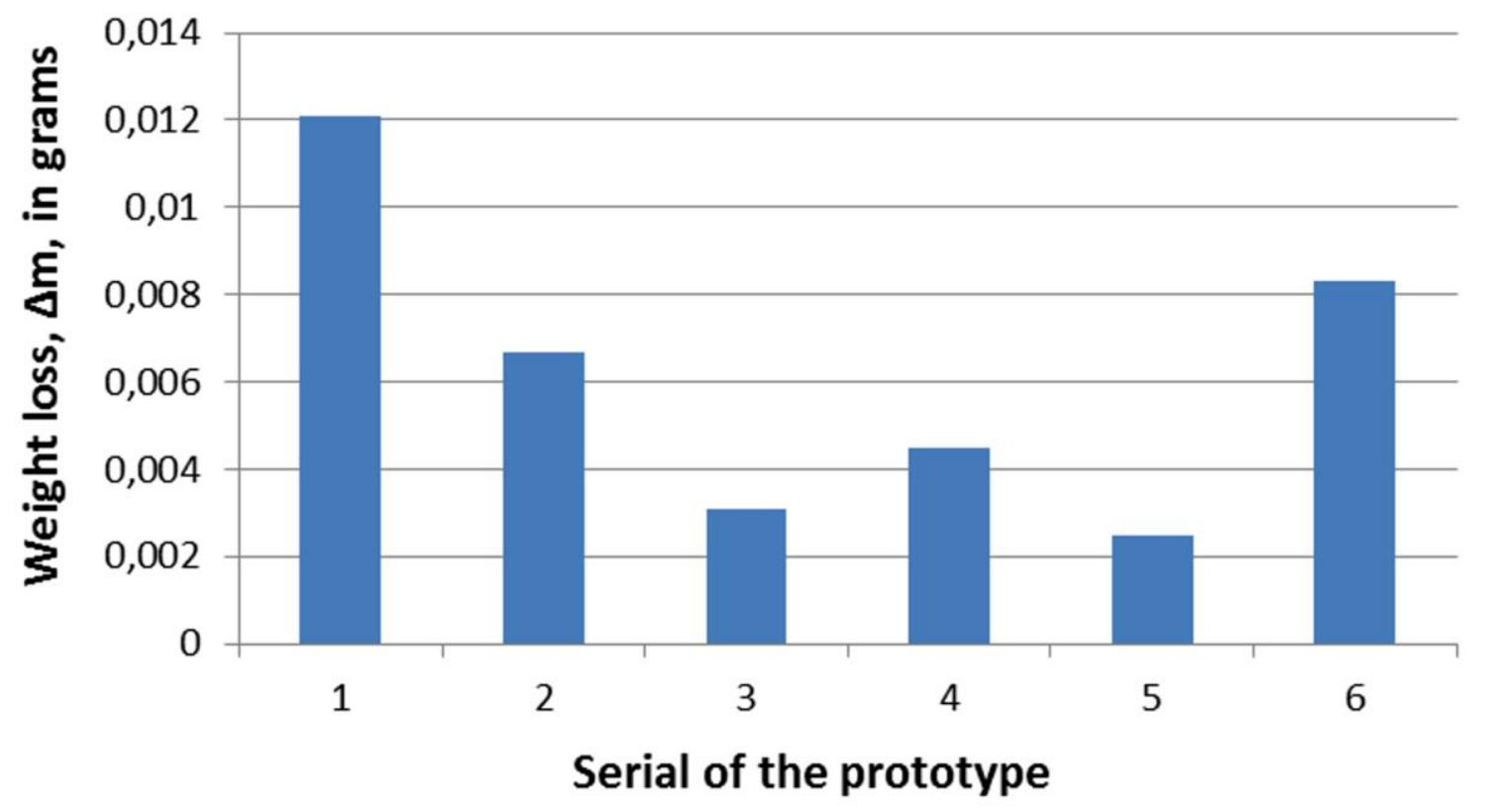

Figure 4. Histogram of the results of the experience on wear resistance

\section{Discussions}

According to the results of abrasion tests of the material of the piston of an internal combustion engine using engine oil modified with additives of nanosized powder of silicon dioxide as a lubricant, it can be seen that wear decreases compared with the control sample in 1.5-2 times at low powder concentrations of $0.9 \%, 1.7 \%, 2.5 \%$. At a higher concentration of $3.4 \%$, material wear is comparable to plain base oil. According to many researchers working in the field of nanotechnology, it has been observed that there are optimal concentrations of nanoparticle addition to materials above and below which the effect of using nanosized additives in composite materials is not noticeable [10,11]. However, the change in the properties of materials exceeds the usual properties by several times when finding the optimal percentage of the addition of nanoparticles. This can be seen in the histogram (Figure 4) and in the photograph of the samples after friction (Figure 3). The minimum value of wear at a concentration of 2.5 (sample 5) is about 2-3 times less than that of control sample 2 .

How can we explain the decrease in wear resistance of sample 6? In our opinion, there are several reasons:

- the number of particles involved in the friction process increases at high concentrations of added nanopowder in the contact zone. This leads to additional local heating, which in turn leads to increased wear of the material;

- the modern understanding of the nature of friction takes into account not only mechanical but also molecular interaction of friction surfaces. As a result, resistance to relative slip called as the molecular component of the friction force arises [1]. This component characterizes the atomic-molecular interactions of the contacting surfaces. In the technical literature, it is called as the adhesive component of the 
friction force. It is possible that nanoparticles with an increased energy potential at high concentrations (above optimal) contribute to the appearance of this phenomenon.

\section{Conclusions}

An experimental test bench for studying the wear resistance of metallic materials called the "friction machine" was developed. It made it possible to test metal samples made of the material of the pistons of the 3S-FE internal combustion engine for wear resistance in the presence of engine oil modified with nanosized additives.

It is economically feasible to use nanosized silica powder as a friction modifier. Its addition to lubricants (motor oils) has a good effect on a friction pair and leads to longterm surface preservation from wear. The life of the engine between repairs can be increased by 2-3 times.

To obtain additives in motor oils based on nanosized silicon dioxide, a method of ultrasonic dispersion in acoustic cavitation mode has proven itself well. Processing time is reduced and the quality of the dispersion is sufficient. A series of experiments with different concentrations of nanopowder in engine oil was carried out. The region of optimal concentrations at which metal wear is the smallest is revealed.

\section{References}

(1) Bazhenov, Yu. V. Fundamentals of the Theory of Machine Reliability: A Training Manual (in Russian), 2nd ed., Rev. and add.; Forum, Higher Education: Moscow, 2014.

(2) Khiterheeva, N. S.; Moshkin, N. I.; Kornopoltsev, V. N.; Sambilov, D. Zh.; Novikov, D. V. Method of Producing an Additive for Motor Oil Based on Nanosized Silicon Dioxide Powder. Patent RU2702760C1, October 11, 2019.

(3) Landau, M. V.; Vradman, L.; Herskowitz, M.; Koltypin, Y.; Gedanken, A. Ultrasonically Controlled Deposition-Precipitation. Journal of Catalysis 2001, 201 (1), 22-36. https://doi.org/10.1006/jcat.2001.3227.

(4) Gedanken, A. Using Sonochemistry for the Fabrication of Nanomaterials. Ultrasonics Sonochemistry 2004, 11 (2), 47-55. https://doi.org/10.1016/j.ultsonch.2004.01.037.

(5) Li, H. J.; Cho, Y. R. Lubricating Oil Composition for Reduction of Friction, Which Includes Nanoporous Particles. Patent RU2512379C1, April 10, 2014.

(6) Strunin, B. P. Additive to Lubricating Oils and Plastic Lubricants. Patent RU2584155C2, May 20, 2016.

(7) Bardakhanov, S. P. Obtaining Nanopowder by Evaporation of the Starting Materials at an Electron Accelerator at Atmospheric Pressure (in Russian). Reports of the Academy of Sciences 2006, 409 (3), 320-323.

(8) Dotsenko, A. I. Fundamentals of tribotechnology (in Russian); Scientific and Publishing Center INFRA-M: Moscow, 2014. 
(9) TEHINTEST LLC. Hardness. Rockwell, Brinell, Vickers hardness test (in Russian) http://www.techintest.ru/statyi/91-tverdost-izmerenie-po-rockvellu-branellyuvikkersu.html (accessed Feb 22, 2020).

(10) Hisatomi, T.; Kubota, J.; Domen, K. Recent Advances in Semiconductors for Photocatalytic and Photoelectrochemical Water Splitting. Chemical Society Reviews 2014, 43 (22), 7520-7535. https://doi.org/10.1039/C3CS60378D.

(11) Huang, L.; Peng, F.; Yu, H.; Wang, H. Preparation of Cuprous Oxides with Different Sizes and Their Behaviors of Adsorption, Visible-Light Driven Photocatalysis and Photocorrosion. Solid State Sciences 2009, 11 (1), 129-138. https://doi.org/10.1016/j.solidstatesciences.2008.04.013.

\section{Information about Authors}

Nadezhda Sergeevna KHiTERHEEVA: Ph.D. in Engineering, (1) Associate Professor, Department "Mechanization of Agricultural Production", Oktemsky Branch Yakutsk State Agricultural Academy; 16 Moiseeva Lane, Oktemtsy, Hangalassky Ulus, Republic of Sakha (Yakutia), 678011, Russia; (2) Faculty of Physics and Technology, Buryat State University; 24a Smolin Str., Ulan-Ude, Republic of Buryatia,670000, Russia; e-mail: kite69@yandex.ru.

Sofya Alekseevna PETROVA: Ph.D. in Agriculture, (1) Associate Professor, Head of the Department "Mechanization of Agricultural Production", Oktemsky Branch Yakutsk State Agricultural Academy; 16 Moiseeva Lane, Oktemtsy, Hangalassky Ulus, Republic of Sakha (Yakutia), 678011, Russia; (2) Faculty of Transport, North-Eastern Federal University named after M.K. Ammosov; 13 Krasilnikov Str., Yakutsk, Republic of Sakha (Yakutia), 677000, Russia; e-mail: sofalo@list.ru.

Varvara Petrovna DRUZHNOVA: D.Sc. in Engineering, Professor, Head of the Department "Operation of Automobile Transport and Car Service", Oktemsky Branch Yakutsk State Agricultural Academy; 16 Moiseeva Lane, Oktemtsy, Hangalassky Ulus, Republic of Sakha (Yakutia), 678011, Russia; (2) Faculty of Transport, North-Eastern Federal University named after M.K. Ammosov; 13 Krasilnikov Str., Yakutsk, Republic of Sakha (Yakutia), 677000, Russia; e-mail: druzvar@mai.ru.

Petr Antonovich BOLOEV: D.Sc. in Engineering, Professor, Department of Engineering, Faculty of Physics and Technology, Buryat State University; 24a Smolin Str., Ulan-Ude, Republic of Buryatia, 670000, Russia; e-mail: lemex74@yandex.ru.

Nikolay Ilyich MOSHKiN: D.Sc. in Engineering, Professor, Department of Engineering, Faculty of Physics and Technology, Buryat State University; 24a Smolin Str., Ulan-Ude, Republic of Buryatia, 670000, Russia; e-mail: univer@bsu.ru.

Marfa Konstantinovna OKHLOPKOVA: Ph.D. in Engineering, Associate Professor, Department "Operation of Automobile Transport and Car Service", Oktemsky Branch Yakutsk State Agricultural Academy; 16 Moiseeva Lane, Oktemtsy, Hangalassky Ulus, Republic of Sakha (Yakutia), 678011, Russia; (2) Faculty of Transport, North-Eastern Federal University named after M.K. Ammosov; 13 Krasilnikov Str., Yakutsk, Republic of Sakha (Yakutia), 677000, Russia; e-mail: omk1265@mail.ru.

Zhargal Nimazhapovich BOTOEV: Postgraduate Student, Institute of Physical Materials Science of the Siberian Branch of the Russian Academy of Sciences; 6 Sakhyanova Str., Ulan-Ude, Republic of Buryatia, 670047, Russia; e-mail: zhargalbatoev06330@gmail.com. 